\title{
Rechtsgeschichte
}

\section{Francisco J. Andrés Santos}

\section{Juristas On His Majesty's Service}


cultura jurídica de la época, ni mucho menos un desajuste del llamado »derecho estatal «, como varios autores sostenían. Por el contrario, la cultura jurídica de la modernidad estaba sustentada en una flexibilidad capaz de integrar numerosos campos normativos. La ductilidad del discurso jurídico fue la regla más que la excepción.

El autor insiste, y nosotros remarcamos, que estos componentes fueron parte de la cultura jurídica de la época moderna, donde la justicia no consistía en la aplicación autónoma de la ley, sino en conservar el orden y mantener la paz por sobre todo. Para ello los jueces debían cumplir con su oficio »castigando y perdonando cuando conviene a la República«.

Concluye el autor señalando que los magistrados capitulares no impusieron mecánicamente la ley regia. La jurisdicción criminal de Córdoba del Tucumán muestra cómo la garantía jurídica estaba más en la conciencia de los jueces que en las leyes del reino, por eso aquella fue más una justicia de jueces que de leyes. El alto grado de poder que tuvieron los magistrados coloniales y peninsulares no era equivalente, agrega Agüero, a un poder discrecional absoluto. El límite estaba impuesto por el mismo orden trascendente. Por consiguiente, justicia y regimiento, sintetizaron un doble orden de representaciones, en el que la primera se decía siempre del rey, mientras que la segunda era propia del pueblo. La justicia, por tanto, no era sólo representación del príncipe, sino también de la República.

La obra de Alejandro Agüero, sustentada en una variada gama de fuentes judiciales coloniales y en un renovado marco historiográfico, complementa los estudios que el campo de la historia social y del derecho argentino poseían sobre dicha temática. Así como el libro de Francisco Tomás y Valiente, El Derecho penal de la monarquía absoluta, supo ser una cita obligada para los especialistas de la justicia penal de Antiguo Régimen, estamos convencidos que el texto reseñado se convertirá, ineludiblemente, en una obra de referencia para el estudio de la justicia penal americana.

\section{Sergio Angeli}

\section{Juristas On His Majesty's Service*}

La gestación, impulso y desarrollo del Imperio español no fue sólo obra de los aguerridos Tercios, o de esforzados e impetuosos curas y misioneros, o de intrépidos conquistadores sin escrúpulos. El Imperio se defendía con las armas y con la fe, sí, pero también con las letras lo mismo que se le atacaba también con ellas (y ahí está la leyenda negra para confirmarlo ${ }^{\mathrm{I}}$ ). Y dentro de los hombres de letras al servicio de Su Católica Majestad estaba por encima de todos el estamento de los letrados, auténtica militia civilis del Imperio. Hombres curtidos en largos y a menudo penosos años de estudio de las leyes en las Universidades, y luego en diversos destinos administrativos o judiciales a lo largo y ancho de los vastos territorios que conformaban los dominios de la rama hispana de los Habsburgo, hasta alcanzar por fin la cúspide con la integración en alguno de los Consejos que constituían con el Rey el gobierno de la Monarquía

\footnotetext{
* Enrique García Hernán, Consejero de ambos mundos. Vida y obra de Juan de Solórzano Pereira (I $575-1655$ ), Madrid: Fundación Mapfre - Instituto de Cultura 2007, 42I pp., ISBN 978-84-98440-56-O
}

\author{
I Sobre ello, véase últimamente \\ Joseph Pérez, La leyenda negra \\ (traducción española de Carlos \\ Manzano), Madrid 2009.
}


Hispánica. Una vida de servicio y sacrificios en aras de un ideal político y religioso, en la que no faltaban intrigas, corruptelas y las más diversas miserias morales, a la vez que una pericia técnica y una capacidad administrativa inigualadas en la Europa de la época. Pero, si bien los letrados, como corporación, actuaron siempre a la sombra del poder real como instancia moderadora (pero también servil) de éste, no obstante, a título individual, no faltaron algunos que contribuyeron decisivamente a la configuración ideológica del régimen y al perfeccionamiento del diseño institucional de un orden político y jurídico tan peculiar y complejo como fue el de la Monarquía Hispánica ${ }^{2}$ - o, más bien, habría que decir la »Monarquía Católica «, en la nomenclatura de la época, dado que los territorios sujetos a la soberanía del Rey "de las Españas " iban mucho más allá de los que integraban los propios reinos hispánicos, lo que explica su extremo activismo en el concierto político europeo al menos hasta la Paz de Wesfalia (I648). Más aún: algunos de esos letrados fueron también genuinos representantes del tipo de intelectual propio del Siglo de Oro español, es decir, celoso defensor de la Monarquía y el Catolicismo, de la gloria y el honor, con una decidida vocación de estilo y un orgullo del empleo de la lengua castellana, porque, como sabiamente escribió Elio Antonio de Nebrija, "siempre la lengua fue compañera del Imperio «. De ahí que algunos de esos letrados rivalizaran con los mismísimos Lope de Vega, Calderón de la Barca, Mateo Alemán o el propio Francisco de Quevedo en el uso artístico de la lengua de Cervantes, incluso para la mera redacción de informes y memoriales administrativos. De todo ello es quizá el ejemplo más sobresaliente don Juan de Solórzano y Pereira, el protagonista del libro que aquí se comenta. En él se dieron cita primorosamente todos esos rasgos característicos del juristaburócrata del Imperio español, pero él los elevó hasta sus más altas cimas y los plasmó brillantemente en sus escritos con una prosa eximia que le asegura un puesto intemporal, no sólo en los anaqueles de la historia de la ciencia jurídica hispana, sino también en los de la historia de la literatura (castellana y neolatina). El libro recensionado es la primera biografía exhaustiva y espléndidamente documentada de esta figura capital en la historia del llamado Derecho indiano, que en su obra es presentado por primera vez en forma sistemática y tendencialmente completa, tras más de I 50 años de conquista y colonización de los territorios americanos por los castellanos. A lo largo de sus páginas no sólo se describen pormenorizadamente los datos fundamentales de su vida y obra (en conjunción inseparable, según veremos después), sino que también se ofrece un cuadro detallado de las vicisitudes vitales atravesadas por cualquier funcionario hispano destacado en las colonias o en la propia villa y corte en la primera mitad del siglo XVII, y los complejos mecanismos de acceso y promoción a los distintos cargos que integraban la burocracia castellana (lo que en la época quiere decir imperial). ${ }^{3}$

En efecto, Juan de Solórzano y Pereira nació en Madrid en I 575 - aún bajo el gobierno del Prudente, que para él siempre sería el modelo de Rey -, en el seno de una familia de larga tradición de servicio al Estado, aunque de cristianos nuevos (lo que le acarrearía numerosos contratiempos a lo largo de su vida). Fue licenciado (I 599) y doctor (I 608) en Leyes por la Universidad de Salamanca, y catedrático de diversas disciplinas en la misma Universidad hasta I609, en que fue nombrado oidor de la Real Audiencia de Lima, cargo que desempeñó hasta I626. Entre I6I6 y I6I 8 ejerció también el cargo de gobernador del
2 Salustiano de Dios, El papel de los juristas castellanos en la conformación del poder político, en: Francisco José Aranda Pérez/ José Damião Rodrigues (eds.), De Re Publica Hispaniae. Una vindicación de la cultura política en los reinos ibéricos en la primera modernidad, Madrid 2008, I27I 48 .

을

3 Sobre este tema sigue siendo de referencia el libro de José M.
GARCÍA MARÍn, La burocracia castellana bajo los Austrias, Madrid 1986, que, sin embargo, no cita el autor. 
distrito minero de Huancavelica, con gran eficacia y reconocimiento. En I 628 vuelve a España y es nombrado fiscal del Consejo de Hacienda, y luego del Consejo de Indias. En I 633 entra por fin como miembro ordinario del Consejo de Indias, en el que actuó hasta I644, año en que hubo de jubilarse por problemas de salud, no sin antes alcanzar el culmen de su carrera administrativa al ser nombrado miembro honorífico del Consejo de Castilla (I642) y caballero de la Orden de Santiago ( (640), lo que le garantizaba el acceso al status de la pequeña nobleza o hidalguía. Murió en Madrid en I655.

Pero, si bien su vida no se aleja demasiado de la biografía corriente de muchos altos funcionarios y juristas de la época, en cambio, su obra dista mucho de constituir una muestra ordinaria de los trabajos de los legistas contemporáneos del autor, y ello por varias razones: primeramente, porque él se especializó en un campo jurídico muy especial, el Derecho indiano, que hasta entonces no había sido objeto de un estudio científico de conjunto, sino sólo de aproximaciones particulares más de orden filosóficomoral o económico-administrativo y comercial que de naturaleza propiamente jurídica; en segundo lugar, porque en vastedad y erudición, su obra se sitúa muy por encima de la de otros juristas castellanos del período, aun tan brillantes como Fernando Vázquez de Menchaca, Antonio Gómez, Diego de Covarrubias o Gregorio López Madera, que no muestran una capacidad semejante para el manejo de muy distintos saberes combinados con un acusado sentido práctico; y, por último, en tercer lugar, porque en su obra se revela como un consumado estilista, tanto en castellano como en latín, con idéntico dominio de los resortes comunicativos de ambas lenguas, lo que lo distingue de cualesquiera otros juristasescritores del período, uno de los pocos que se han ganado el calificativo de maestro clásico de la lengua castellana. Por todas estas razones, al menos, Solórzano merece ser situado entre las cumbres de la ciencia jurídica española y latinoamericana, y sorprende que hasta ahora no hubiera sido objeto de un tratamiento biográfico a la altura de su envergadura intelectual. El libro comentado viene a cubrir esta laguna adecuadamente.

En la monografía se entremezclan con soltura los aspectos vitales con los proyectos políticos e intelectuales del autor biografiado, las vicisitudes de su vida pública y privada con los rasgos metodológicos y los elementos doctrinales de sus obras, así como la trascendencia ulterior de estas últimas, todo ello dentro del contexto socio-político en que se inscriben. El relato cronológico no lastra el desarrollo conceptual, de modo que el autor del libro no duda en romper en ocasiones el hilo argumental de la sucesión de peripecias vitales de Solórzano para adentrarse en los problemas conceptuales y constructivos que presiden sus textos, o para narrar acontecimientos históricos relevantes en que directa o indirectamente se hubiera visto envuelto el protagonista. En este sentido, el libro destaca adecuadamente al menos cinco núcleos temáticos que constituyen sendos ejes vertebradores de la propuesta solorciana, a saber: I) la admiración y ensalzamiento de la Monarquía Hispánica y su acción política y colonizadora; 2) su "conciencia de clase " como letrado, consejero y servidor de la Corona; 3 ) su preocupación por las cuestiones económicas y financieras; 4) su concepción del Derecho como algo intrínsecamente unido a la Historia y la Política; y 5) su recia defensa de los derechos de los indios y, sobre todo, de los criollos asentados en América. Veamos ahora brevemente cada uno de estos puntos, según son tratados a lo largo del volumen comentado. 
Solórzano fue siempre un celoso defensor de la Corona, y »la grandeza de España era su obsesión « (72), de ahí que, aunque pudiera eventualmente criticar algunos excesos, no cesa de alabar a sus reyes y a ver en el »descubrimiento « y la »evangelización « (léase conquista y colonización) una »ingente e incomparable hazaña «. Sentía devoción por Carlos V, Felipe II era para él el monarca modélico para Felipe IV, y la pérdida de Felipe III la consideró trágica e intempestiva ... Incluso los validos - singularmente, el Conde-Duque de Olivares (dueño del poder entre I622 y I643) - merecen su encomio (I68). Todo con tal de proteger la grandeza y dignidad de la Monarquía Hispánica frente a sus enemigos materiales y espirituales (pues no en vano ya en su época la leyenda negra circulaba con provecho por toda Europa). Hasta tal punto es así, que nuestro jurista llegó a enfrentarse incluso a la misma Inquisición con tal de defender los derechos de su Monarca, como lo evidencia el hecho de que la segunda parte de su De Indiarum Iure (De Gubernatione Indiarum, de I639) fuera condenada por el Santo Oficio romano e incluido en el Index Librorum Probibitorum en 1647 (y allí se mantuviera aún en la edición de I900), a pesar de las airadas protestas del gobierno de Su Católica Majestad, y ello a consecuencia de su vigorosa vindicación del Patronato Regio en Indias y sus prerrogativas, frente a las pretensiones de recuperación del control y conservación de privilegios por las autoridades eclesiásticas (282-288). Ahora bien, todo esto no significa, empero, que su obra estuviese absolutamente carente de observaciones críticas hacia el poder político de su época. Como se aborda correctamente en el libro, Solórzano, a pesar de su olivarismo moderado, se mostró muy receloso respecto al proyecto de »Unión de Armas « de Olivares, es decir, el in- tento de concentración de esfuerzos de todos los territorios de la Monarquía en torno a la figura del Monarca en cuanto Rey de Castilla. Nuestro jurista fue más bien partidario de una concepción plurinacional de la Monarquía Hispánica, donde los naturales de cada uno de los territorios integrantes de la misma no sólo siguieran gozando de sus derechos y costumbres tradicionales, sino también que tuvieran participación (dentro de los estándares de la época) en el gobierno propio, con el Rey como soberano único, pero singular de cada uno de los reinos (304). Es decir, »unidad, pero no uniformidad « (264). Paradójicamente, hoy se revela esta visión de Solórzano mucho más "postmoderna « - y, por tanto, cercana al sentir más actual - que la "moderna « de Olivares, a pesar del medievalismo que la inspira (al igual que a otras concepciones jurídico-políticas del autor, según veremos). Solórzano se sitúa así en la línea del "pactismo" tradicional, sustentado también por los autores de la Escuela de Salamanca y por los jurisconsultos de los reinos no-castellanos de la Monarquía, especialmente catalano-aragoneses.

Un segundo aspecto capital de la obra solorciana es el de su elevada autoconciencia respecto a su labor como consejero real. Al igual que otros muchos letrados, Solórzano se propuso como objetivo central de su actividad profesional e intelectual el convertirse en miembro de alguno de los altos Consejos de la Monarquía. Finalmente lo consiguió, como vimos, en I 629 (sin duda por la intervención directa del CondeDuque). Mas su ambición por formar parte de esos altos organismos no obedecía tan solo a un prurito de orden personal y profesional o a un afán de gloria y riqueza, sino que se encontraba íntimamente ligada a su concepción del poder político: en la misma línea que otros escritores políticos del período (Pedro Fernández de $\mathrm{Na}$ - 
varrete, Pedro de Rivadeneira, Lorenzo Ramírez de Prado, etc.), Solórzano propugna la necesidad del Consejo para sostener la Monarquía (I66, 267): ésta sólo se justifica como poder absoluto en la medida en que se ve acompañada en sus decisiones por el consejo como representante de algún modo de la comunidad política, lo cual garantiza que el poder real busque el bien común y, por tanto, se convierta en poder legítimo. La participación en el Consejo se hace así, pues, misión crucial en la vida y obra de Solórzano. Ello explica, en parte, que toda su obra esté repleta de referencias a cuestiones personales y detalles autobiográficos (de lo que ha obtenido gran aprovechamiento el autor del libro reseñado), en la medida en que su propia persona constituye en su imaginario una ejemplificación del modo de proceder del »buen consejero" como pieza esencial del complejo mecanismo de funcionamiento de la Monarquía burocrática moderna (I96). Todo ello se evidencia también, no sólo a través de los innumerables documentos que redactó a petición del Monarca en los diversos organismos de que formó parte y las funciones que desempeñó, sino también en la elaboración de una ambiciosa obra literaria tardía, los Emblemata Centum Regio-Politica (I653), dirigida explícitamente a la ilustración y buena formación del Rey (o, más bien, de los futuros monarcas), en la línea de los tradicionales »espejos de príncipes « que proliferaron en la literatura política europea, también en la española, desde mediados del siglo XVI, desde que se comprobó por parte de la intelectualidad humanista que la Monarquía absoluta había venido para quedarse (desapareciendo así los sueños de una restauración del republicanismo antiguo), y los eruditos resolvieron que, ya que resultaba imposible deshacerse de un príncipe soberano, al menos podía intentarse su sujeción a un orden de valores por medio de la educación (cristiana, por supuesto). Solórzano se inscribe en esta tradición, si bien esta obra desborda con mucho las pretensiones iniciales de un espejo de príncipes, para recoger propiamente su "cosmovisión política « (294) en una forma compleja que requiere aún de una investigación en profundidad (que, obviamente, el autor no aborda en este libro).

Una tercera clave de comprensión de la obra solorciana tiene que ver con sus preocupaciones de orden económico. ${ }^{4}$ Tanto en su faceta de administrador y consejero como en la de escritor jurídico-político, Solórzano se mostró siempre atento a la necesidad de buscar vías de incrementar la percepción de recursos económicos para la Corona, reducir gastos innecesarios y mejorar las técnicas de producción (especialmente en la minería, de la que hubo de convertirse en gran especialista, muy a su pesar). Esta preocupación por los aspectos económicos del gobierno no obedecía a ninguna inquietud intrínseca suya, sino que se hallaba necesariamente vinculada a sus convicciones de orden político, es decir, la defensa a ultranza del modelo de monarquía habsbúrgica y sus designios dinásticos. Solórzano era consciente de que la crisis económica significaría la ruina del Imperio - y, de hecho, sostiene en alguna ocasión que la decadencia del comercio era el principal problema de la Monarquía (I 29) -, por lo que arbitrar medidas que coadyuvaran a solventar esa situación se convertía en un objetivo prioritario: de ahí que no dude incluso en manifestarse en contra de los planes del gobierno cuando considere que son perjudiciales para ese fin superior, como es el caso de la subida de impuestos, a la que se opuso no por principio dogmático o por un prurito de preservación de los derechos de los súbditos, sino por puras razones técnicas, al considerar que ello conduciría a una reducción de ingresos

\footnotetext{
4 Esta temática ha sido abordada últimamente de forma monográfica por Santiago Hierro AníBARRo, Economía y Derecho mercantil en la obra de Juan de Solórzano Pereira, Madrid, Barcelona, Buenos Aires 2008.
} 
más que a su incremento: ¡una sorprendente anticipación barroca de la curva de Laffer! Y este posicionamiento político-ideológico explica también su oposición a toda actuación económica que pudiera menoscabar los intereses estratégicos de la Monarquía hispánica, como por ejemplo su cerrado rechazo (aun sin nombrarlo) de los postulados protolibrecambistas del Hugo Grocio del Mare Liberum (I 54, I64). Ello no implica, sin embargo, que no tuviera cierta curiosidad intelectual por el análisis de algunas figuras jurídico-económicas, singularmente aquellas que sólo tenían presencia en la realidad indiana, como la encomienda, ${ }^{5}$ de la que incluso él mismo resultó beneficiado en I 636 (206), lo que explica en parte sus pocos escrúpulos a la hora de defender teóricamente las pretensiones de los encomenderos, incluso frente a las exigencias morales y los intentos de control por parte de la Corona (222).

Un cuarto aspecto esencial de la doctrina del biografiado es la intrínseca conexión con la Historia en su visión del Derecho. Solórzano contempla la Historia no sólo como una magistra vitae, sino también como magistra iuris y magistra politicae (75 ss.). Su inclinación por el cultivo de la Historia y su vinculación con el Derecho es muy temprana y no es un capricho personal, sino que se encuentra igualmente en otros muchos autores en la estela del humanismo europeo. Su objetivo en realidad era usar tanto el Derecho como la Historia para llegar a la Política (257). De ahí que en todos sus textos doctrinales se observe una continua combinación de consciencia histórica con dimensión política, sin que el formalismo jurídico ahogue en ningún caso esa inclinación, y que en sus obras abunde la referencia a la peripecia personal como elemento integrante e ineludible del análisis institucional. En esto, ciertamente, no puede verse a
Solórzano como un adelantado en su tiempo de fenómenos actuales, por desgracia.

Por fin, queda un último aspecto fundamental de la obra de Solórzano que resulta de gran trascendencia en esta sede, cual es el de su defensa constante del indio, pero también de los criollos (los beneméritos de Indias), incluso en ocasiones frente a los juicios e intereses de la Corona. Si bien su justificación de la Conquista y colonización de América por los castellanos (De Iure Indiarum, tomo I; Política Indiana, libro I) muestra aún rasgos muy medievalizantes, ${ }^{6}$ en cambio, en su actitud respecto a los indígenas se acerca mucho más a los postulados de la Escuela de Salamanca, es decir, a la consideración de los naturales de las Indias no como individuos inferiores susceptibles de esclavitud o pura explotación laboral, sino como verdaderos "vasallos " del rey de Castilla, esto es, súbditos libres, sujetos de derecho, aunque de capacidad reducida, personae miserabiles ${ }^{7} \mathrm{y}$, por ende, necesitadas de dirección y defensa en aras de su »evangelización « (léase »civilización ", esto es, sometimiento y aculturación). Esta actitud paternalista tiene, no obstante, consecuencias jurídicas, tanto en el plano económico (liberación de los indios de ciertas formas extremas de explotación laboral) como jurídico (posibilidad de cierta autoorganización de las comunidades indígenas en forma de "república de los indios", frente a la »república de los españoles«), que Solórzano tiene buen cuidado en describir en sus obras más significativas. Esta actitud de respeto y conmiseración hacia los indígenas no quedó sólo recluida en los límites de sus escritos - aun siendo esto importante, con todo -, sino que presidió igualmente sus actuaciones públicas en Indias - en particular durante su período de gobierno del distrito de Huancavelica (I39 ss.) - y también en su actividad de consejo cerca de la Corte madrileña (2 I 5 ,
5 Cfr. al respecto Francisco J. ANDrés SANTos, Encomienda y usufructo en Indias. Reflexiones romanistas en torno a la doctrina de Juan de Solórzano y Pereira, en: Tijdschrift voor Rechtsgeschiedenis 59 (200I) 245-270.

6 James Muldoon, Solorzano's De indiarum iure: Applying a Medieval Theory of World Order in the

은 Seventeenth Century, en: Journal ลํ. of World History 2 (I99I) 29-45.
$7 \mathrm{Al}$ respecto, cfr. Thomas Duve, Sonderrecht in der Frühen Neuzeit. Studien zum ius singulare und den privilegia miserabilium personarum, senum und indorum in Alter und Neuer Welt, Frankfurt am Main 2008, I66ss. 
280-282). En una muestra más de la coherencia que, en general, adornó siempre su vida y obra, nuestro autor llegó a toparse con problemas con la Corona como consecuencia de su actitud tuitiva hacia los indios: en efecto, en I647 el manuscrito de la segunda parte de su De indiarum iure (De Gubernatione) sufrió una severa censura debido a sus referencias demasiado explícitas a los malos tratos sufridos por los indios a manos de los españoles, referencias que finalmente Solórzano no pudo por menos de suprimir en la edición definitiva de la obra ante el manifiesto »disgusto « expresado por la Corona, máxime tratándose el autor de un consejero tan próximo al poder real (I6I), mientras que, curiosamente, en este punto la obra encontraba el respaldo expreso de la Santa Sede (I62). El episodio refleja perfectamente el estado de ánimo reinante, ya que la lucha por la hegemonía entre las potencias europeas del momento no se libraba sólo en los campos de batalla, sino también en el terreno de la propaganda.

En paralelo con esto - y sin que en ocasiones dejen de aflorar contradicciones - Solórzano asumió también la firme defensa de las prebendas de los españoles asentados en las colonias (los criollos), que en algunos casos se extendían ya por varias generaciones (beneméritos de Indias). No es claro si esta disposición obedece a una verdadera convicción respecto a los »derechos « legítimos de los españoles y sus descendientes sobre las tierras conquistadas y sus habitantes, o bien está lastrada por su pertenencia a una familia de dilatada presencia en las Indias e incluso a sus propios objetivos económicos (que, como el autor del libro reseñado resalta agudamente, no fueron escasos, como se desprende de sus disposiciones testamentarias, 3 Io ss.), pero lo cierto es que en sus obras doctrinales y en sus dictámenes y resoluciones aparece a menudo una actitud inequívoca de búsqueda de una interpretación de la ley lo más favorable posible a los intereses de los propietarios criollos (como una suerte de aristocracia colonial), incluso frente a la posición oficial del gobierno, por entender que eran »leales vasallos de la Corona « similares a los de los otros territorios de la Monarquía y, en consecuencia, merecedores de iguales derechos, singularmente el de ser juzgados por ellos mismos (3 I). El autor del libro subraya un extremo que normalmente ha pasado desapercibido, pero que resulta muy pertinente a lo que constituye la temática central de este volumen de Rechtsgeschichte, como es el de la presunta influencia de la doctrina solorciana en el pensamiento de los independentistas latinoamericanos - singularmente en el argentino Mariano Moreno (I778-I8II) - en la búsqueda de una identidad propia que los diferenciara esencialmente de los españoles (28-30). Se trata sin duda de una dimensión de la inmensa herencia intelectual de Solórzano Pereira de extraordinaria relevancia en el momento presente, que aún no ha sido suficientemente analizada por la historiografía (y que el autor de este libro tiene el mérito de haber apuntado) y que lo vuelve a perfilar como un pensador adelantado a su tiempo y aún de sorprendente actualidad.

Francisco J. Andrés Santos 